\title{
Miswiring of Limbic Thalamocortical Projections in the Absence of Ephrin-A5
}

\author{
Daniela Uziel,, ${ }^{1,2}$ Sven Mühlfriedel, ${ }^{1}$ Kostas Zarbalis,, ${ }^{3}$ Wolfgang Wurst, ${ }^{3}$ Pat Levitt, ${ }^{4}$ and Jürgen Bolz ${ }^{1}$ \\ 1 Universität Jena, Institut für Allgemeine Zoologie und Tierphysiologie, 07743 Jena, Germany, 2 Programa de \\ Neurobiologia, Instituto de Biofísica Carlos Chagas Filho, Universidade Federal do Rio de Janeiro, 21949-590 Rio de \\ Janeiro, Brazil, ${ }^{3}$ Max-Planck-Institut für Psychiatrie, 80804 Munich, Germany, and ${ }^{4}$ Department of Neurobiology, \\ University of Pittsburgh School of Medicine, Pittsburgh, Pennsylvania 15261
}

\begin{abstract}
Axon guidance cues of the ephrin ligand family have been hypothesized to regulate the formation of thalamocortical connections, but in vivo evidence for such a role has not been examined directly. To test whether ephrin-mediated repulsive cues participate in sorting the projections originating from distinct thalamic nuclei, we analyzed the organization of somatosensory and anterior cingulate afferents postnatally in mice lacking ephrin-A5 gene expression. Projections from ventrobasal and laterodorsal nuclei to their respective sensory and limbic cortical areas developed normally. However, a portion of
\end{abstract}

limbic thalamic neurons from the laterodorsal nucleus also formed additional projections to somatosensory cortical territories, thus maintaining inappropriate dual projections to multiple cortical regions. These results suggest that ephrin-A5 is not required for the formation of normal cortical projections from the appropriate thalamic nuclei, but rather acts as a guidance cue that restricts limbic thalamic axons from inappropriate neocortical regions.

Key words: wiring molecules; axonal guidance; cortical development; limbic system; thalamocortical circuits; ephrin
The cerebral cortex is parceled into functional areas that have specific patterns of input and output projections. The medial cortical areas (prefrontal, cingulate, and retrosplenial cortices), which are part of the limbic system, receive afferents from the mediodorsal group and laterodorsal thalamic nuclei (Domesick, 1972; Van Groen and Wyss, 1992), whereas neocortical areas, such as the somatic sensorimotor cortex, receive afferents from the ventrolateral group of nuclei (Fabri and Burton, 1991 and references therein). This precise areal organization occurs from the initiation of the projection during development. Thus, thalamic afferents normally bypass nontarget regions to innervate their appropriate cortical targets (Wise and Jones, 1978; Crandall and Caviness, 1984; De Carlos and O'Leary, 1992; Agmon et al., 1995). It has been suggested that guidance molecules may regulate the early specificity (Barbe and Levitt, 1992; Bolz and Götz, 1992; Mann et al., 1998; Molnár and Blakemore, 1991, 1995). For example, during normal development, limbic cortical areas express the limbic system-associated membrane protein (LAMP), a cell adhesion molecule that has been shown to act as a guidance and branch signal for thalamic axons in vivo and in vitro (Barbe and Levitt, 1992; Mann et al., 1998). Several authors demonstrated that the tyrosine kinase receptor ligand ephrin-A5 is expressed in the somatosensory cortex at a embryonic time period when thalamic fibers invade the cortex and that one of its receptors, EphA5, is expressed in the medial group of thalamic nuclei

\footnotetext{
Received May 2, 2002; revised July 12, 2002; accepted July 22, 2002.

This work was supported by National Institutes of Mental Health Grant MH45507 (P.L.) and the Interdisziplinäres Zentrum für Klinische Forschung Jena (J.B.). D.U. is a fellow from the Coordenação de Aperfeiçoamento de Pessoal de Nível Superior Foundation of Brazil.

Correspondence should be addressed to Dr. Jürgen Bolz, Universität Jena, Institut für Allgemeine Zoologie und Tierphysiologie, Erbertstrasse 1, 07743 Jena, Germany. E-mail bolz@pan.zoo.uni-jena.de.

Copyright (C) 2002 Society for Neuroscience $0270-6474 / 02 / 229352-06 \$ 15.00 / 0$
}

that normally project to limbic cortex (Gao et al., 1998, Mackarehtschian et al., 1999; Vanderhaeghen et al., 2000). The expression patterns are consistent with ephrin-A5 acting as a repulsive cue for limbic thalamic axons, similar to their role in regulating topographic retinotectal (Cheng et al., 1995; Drescher et al., 1995, 1997), hippocampal (Stein et al., 1999; Brownlee et al., 2000), and thalamocortical (Vanderhaeghen et al., 2000) projections.

In agreement with this hypothesis, ephrin-A5 inhibits in vitro the outgrowth of neurites from medial (limbic) thalamic neurons but has no effect on lateral (nonlimbic) thalamic neurons (Gao et al., 1998). In addition, it acts as a repulsive axonal guidance signal for limbic thalamic axons, whereas for most nonlimbic thalamic fibers, it exhibits no guidance activity (Mann et al., 2002). To test this proposed guidance role more directly, we examined the targeting of thalamocortical projections in the absence of ephrin-A5 using a gene-targeted mouse line in which the ephrin-A5 transcript and protein are absent (Knöll et al., 2001). Our findings suggest that ephrin-A5 contributes to the precision of developing cortical circuitry by repelling limbic thalamic axons to prevent penetration into neocortical areas.

\section{MATERIALS AND METHODS}

Thirteen wild-type (+/+) and 20 ephrin-A5 knock-out (-/-) animals were used in this study. Ephrin-A5 -/- mice are the same described by Knöll et al. (2001). At postnatal day 8 (P8) (day of birth is P0) animals were perfused with $4 \%$ paraformaldehyde, and the brains prepared for standard 1,1'-dioctadecyl-3, 3, 3', 3'-tetramethylindocarbocyanine perchlorate (DiI) (Molecular Probes, Eugene, OR) labeling as described previously (Novak and Bolz, 1993). Crystals were inserted into different rostrocaudal levels of the anterior cingulate or primary somatosensory cortex. In some cases, 4-(4-(dihexadecylamino) styryl)- $N$-methylpyridinium iodine (DiASP) (Molecular Probes) was used for double labeling. Vibratome sections $(100 \mu \mathrm{m})$ were mounted for visualization on a Zeiss (Oberkochen, Germany) Axiovert or a Nikon (Tokyo, Japan) E800 fluorescence microscope. The thalamic nuclei were identified according to their rostrocaudal and ventrodorsal position, comparing DiI-labeled slices counterstained with 
Table 1. Number of retrogradely labeled neurons in different thalamic nuclei after injection of lipophylic tracers in sensorimotor (A-I, M-P) and cingulate cortex (J-K, O-T) in normal (M-T) and ephrin-A5 knock-out (A-L) mice

Ephrin-A5 -/-: injections in

Ephrin-A5 -/-: injections in sensorimotor cortex

\begin{tabular}{|c|c|c|c|c|c|c|c|c|c|c|c|c|c|c|c|c|c|c|c|c|}
\hline & \multirow[b]{2}{*}{ A } & \multirow[b]{2}{*}{ B } & \multirow[b]{2}{*}{$\mathrm{C}$} & \multirow[b]{2}{*}{$\mathrm{D}$} & \multirow[b]{2}{*}{$\mathrm{E}$} & \multirow[b]{2}{*}{$\mathrm{F}$} & \multirow[b]{2}{*}{$\mathrm{G}$} & \multirow[b]{2}{*}{$\mathrm{H}$} & \multirow[b]{2}{*}{ I } & & & \\
\hline & & & & & & & & & & $\mathrm{J}$ & $\mathrm{K}$ & $\mathrm{L}$ & M & $\mathrm{N}$ & $\mathrm{O}$ & $\mathrm{P}$ & Q & $\mathrm{R}$ & $\mathrm{S}$ & $\mathrm{T}$ \\
\hline VB & 301 & 229 & 260 & 51 & 236 & 265 & 246 & 313 & 262 & 0 & 0 & 0 & 459 & 299 & 204 & 272 & 0 & 0 & 0 & 0 \\
\hline Po & 253 & 76 & 155 & 25 & 74 & 162 & 55 & 79 & 180 & 40 & 0 & 25 & 282 & 78 & 177 & 179 & 16 & 94 & 3 & 109 \\
\hline LP & 2 & 3 & 27 & 0 & 5 & 17 & 0 & 0 & 10 & 0 & 94 & 106 & 0 & 2 & 2 & 1 & 4 & 16 & 46 & 176 \\
\hline LD & 16 & 3 & 33 & 0 & 14 & 5 & 3 & 13 & 32 & 73 & 132 & 186 & 0 & 0 & 0 & 0 & 85 & 165 & 402 & 488 \\
\hline AV & 0 & 0 & 0 & 0 & 0 & 0 & 0 & 0 & 0 & 0 & 0 & 0 & 0 & 1 & 0 & 0 & 8 & 6 & 23 & 10 \\
\hline $\mathrm{AM}$ & 0 & 0 & 0 & 0 & 0 & 0 & 0 & 0 & 0 & 0 & 0 & 0 & 0 & 0 & 0 & 0 & 0 & 4 & 0 & 0 \\
\hline $\mathrm{AD}$ & 0 & 0 & 0 & 0 & 0 & 0 & 0 & 0 & 0 & 0 & 0 & 0 & 0 & 0 & 0 & 0 & 0 & 0 & 3 & 0 \\
\hline MD & 0 & 0 & 0 & 0 & 0 & 0 & 0 & 0 & 0 & 0 & 0 & 5 & 0 & 0 & 0 & 0 & 0 & 0 & 12 & 0 \\
\hline
\end{tabular}

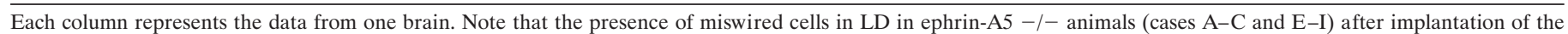
tracer in sensorimotor cortex. AV, Anteroventral nucleus; AM, anteromedial nucleus; AD, anterodorsal nucleus; MD, mediodorsal nucleus of the thalamus.

4',6'-diamidino-2-phenylindole dihydrochloride with $25 \mu \mathrm{m}$ cresyl violetstained sections of P8 animals and with an anatomical mouse atlas (Franklin and Paxinos, 1997). The investigators were blind to the genotype until after initial examination and mapping. All cases were excluded in which crystals entered subcortical white matter, which resulted in intensively labeled corticocortical fibers. All sections were photographed at various magnifications, and, in most cases (eight ephrin-A5 $+/+$ and 12 ephrin-A5 -/-), the number of cells in each thalamic nucleus in all sections was counted (Table 1) and plotted on charts (see Figs. 3, 4). The percentage of misrouted cells was calculated as number of cells identified in the laterodorsal nucleus of the thalamus (LD) plus the cells in the lateroposterior nucleus (LP) divided by the number of retrogradely labeled cells in the ventrobasal complex (VB). Because the posterior nucleus of the thalamus (Po) projects to both anterior cingulate and parietal cortices, it was not possible to identify putative misrouted cells in this nucleus. Statistical significance between genotypes was determined using the Mann-Whitney $U$ test.

\section{RESULTS}

Diff usion of DiI or DiASP from cortical injection sites resulted in readily visible fibers along their pathway in the white matter and internal capsule and retrogradely labeled cells in different thalamic nuclei. Analysis of cresyl violet-stained sections revealed normal cytological organization of the cerebral cortex and thalamic nuclei of ephrin-A5 -/- animals (Fig. $1 A, B$ ). Implantation of crystals along the anterior cingulate cortex resulted in expected intense labeling of neurons in dorsal thalamic regions, including LD and LP nuclei. The pattern of labeling was identical in both $+/+$ and $-/-$ mice. Cingulate injections also labeled neurons in a region ventral to $\mathrm{LD}$, corresponding to the Po. Crystals localized more rostrally in the anterior cingulate/prefrontal cortex boundary also labeled axons from the anterior and medial thalamic group, as described previously (Domesick, 1972, see cases Q-T). Table 1 illustrates the number of retrogradely labeled cells in each nucleus of $+/+$ (Table $1, \mathrm{Q}-\mathrm{T}$ ) and $-/-$ animals (Table $1, \mathrm{~J}-\mathrm{L}$ ), with a similar degree of labeling in both genotypes. We did not identify even a single case in which abnormal or ectopic cells were found in the thalamus of ephrin-A5 -/- animals after implantation of DiI in the anterior cingulate cortex.

Dye crystals placed in the somatic sensorimotor region of $+/+$ mice resulted in a large number of retrogradely labeled cells ventral and laterally in the thalamus, in the region correspondent to Po and the VB (Table 1, M-P; Fig. 1C; see Fig. 4). In rare instances, one or two cells were present in dorsal and posterior regions of the thalamus, corresponding to LP. Figure 3 depicts a representative case (Table 1 , brain $\mathrm{A}$ ) showing both the injection
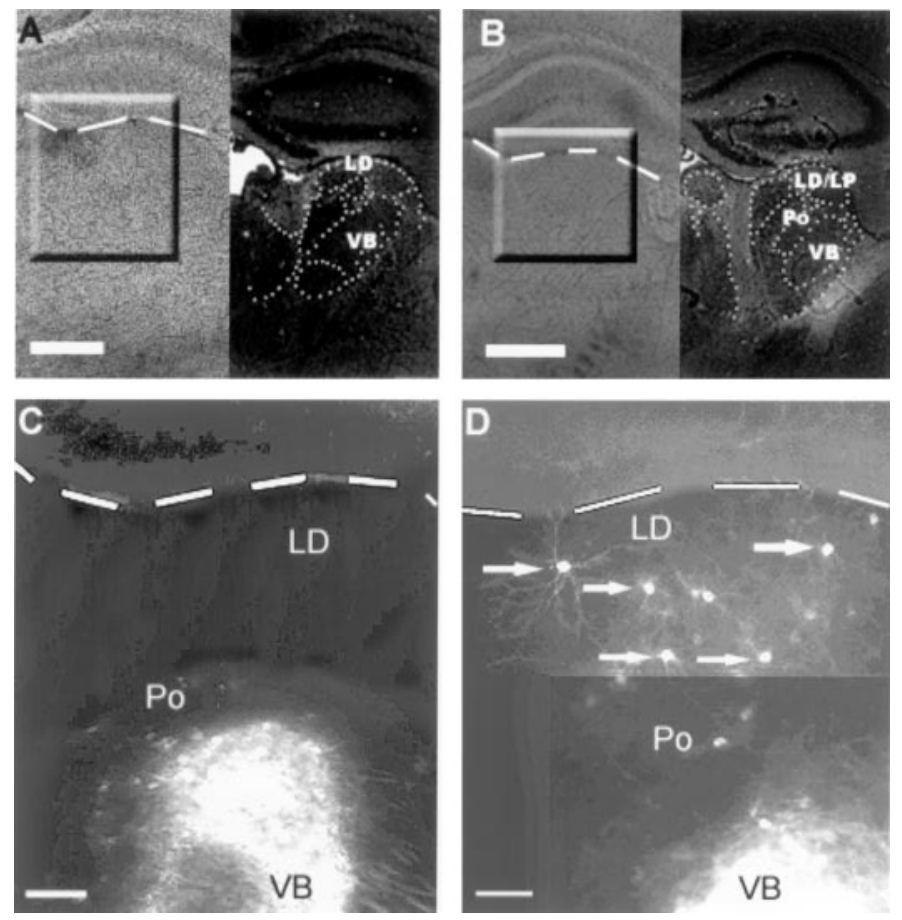

Figure 1. Low-power photomicrographs of coronal brain sections from wild-type $(A, C)$ and ephrin-A5 knock-out $(B, D)$ animals after implantation of DiI in the sensorimotor cortical region of $\mathrm{P} 8$ mice. $A$ and $B$ show bright-field photographs of the slices labeled with DiI (left) and cresyl violet staining for identification of the thalamic nuclei (right). $C$ and $D$ correspond to the marked areas in $A$ and $B$, and the dashed line indicates the border between hippocampus and dorsal thalamus. Note that, in $C$, cells are concentrated in ventral portions of the thalamus, a region corresponding to Po and VB. In $D$, after placement of DiI in a cortical region similar to $C$, cells are stained not only in the $\mathrm{Po} / \mathrm{VB}$ region but also dorsally in LD; some of these cells are indicated by an arrow. Scale bars: $A, B, 200 \mu \mathrm{m} ; C, D, 100 \mu \mathrm{m}$.

site and charts of three of eight sections with retrogradely labeled cells. The extent and patterns of labeling of $\mathrm{VB}$ and Po were obtained in the ephrin-A5 -/- mice (Table $1, \mathrm{~A}-\mathrm{I}$ ), but, in addition, clusters of dorsally located cells were retrogradely filled after implantation of DiI in the sensorimotor cortex of ephrin-A5 $-/-$ mice (Figs. $1 D, 2 A, B)$. The ectopic cells were identified in $90 \%$ of the cases studied, with a range in the extensiveness of the 

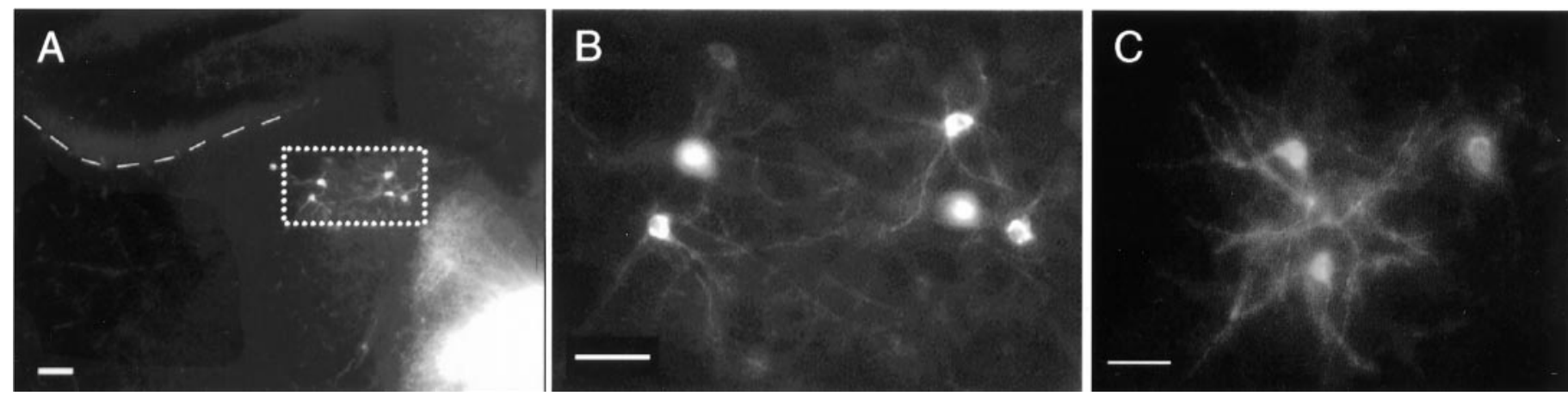

Figure 2. Low-power $(A)$ and high-power $(B)$ photomicrographs of ectopic-labeled cells in dorsal thalamus of knock-out animals after implantation of DiI in the sensorimotor cortex. $C$, For comparison, retrogradely labeled neurons in the same thalamic region after placement of DiI in the cingulate cortex of normal animals. The dashed line indicates the border between hippocampus and dorsal thalamus. See Figure 1 . Scale bars: $A, 100 \mu$ m; $B, C$, $50 \mu \mathrm{m}$.
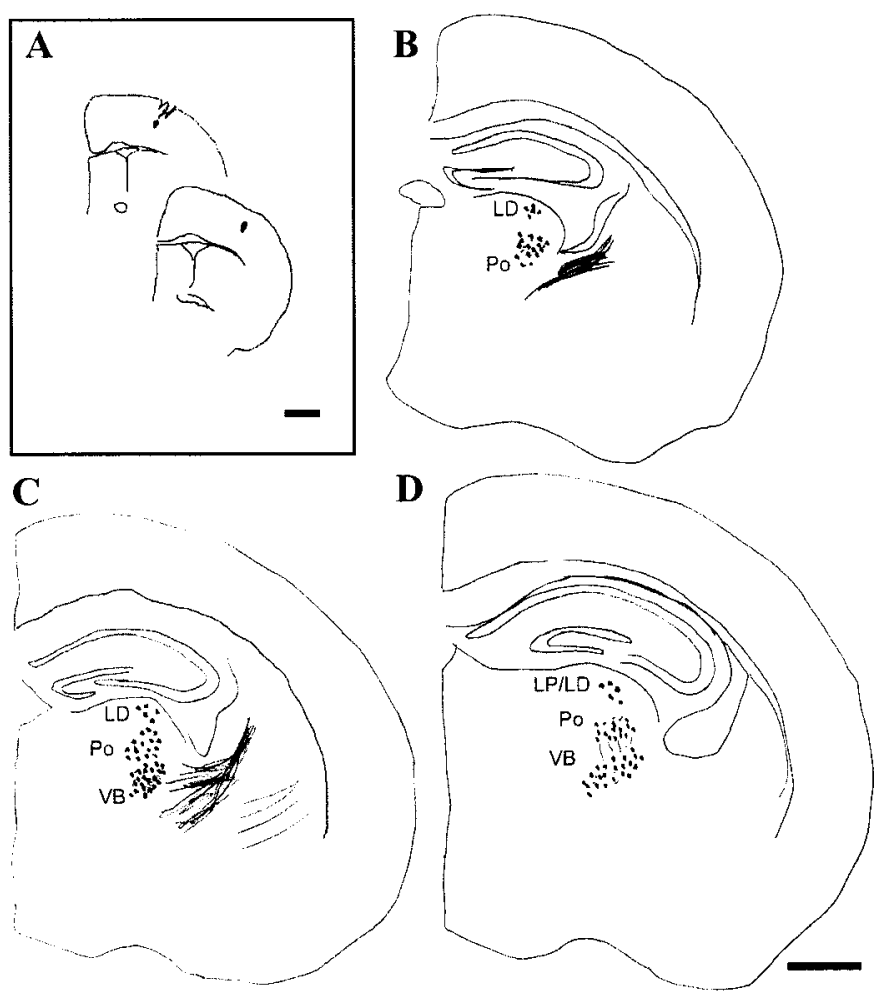

Figure 3. Thalamocortical projections in an ephrin-A5-deficient animal. $A$, Tracer injection site; DiI crystals in the somatosensory cortex were confined to two consecutive $100-\mu \mathrm{m}$-thick sections. $B-D$, Charts of sections with retrogradely labeled cells in the thalamus and thalamocortical axons extending through the internal capsule. Scale bars: $A, 1 \mathrm{~mm}$; (in $D$ ) $B-D, 500 \mu \mathrm{m}$.

retrograde labeling (Table 1 ). These cells typically occupied more anterior parts of the dorsal thalamus, which corresponds anatomically to LD, although some cells were also found more caudally in LP. Most of these labeled cells were localized in a region between interaural 2.34, bregma -1.46 and interaural 2.10, bregma -1.70 (sections represented in Figs. 3, 4).

In the double labeling experiments of ephrin-A5 -/- mice, in which different crystals of carbocyanine dyes were introduced simultaneously in the anterior cingulate (DiASP) and sensorimotor (DiI) cortices, DiI-labeled cells were identified among DiASPlabeled ones in LD, LP, and Po (Fig. 4). Although there was an obvious anatomical overlap of the two populations, double- labeled cells were never identified. Morphologically, the ectopic thalamic neurons after sensorimotor cortex labeling in the $-/-$ mice exhibited large dendritic arbors, very similar to ones obtained after implantation of crystals of DiI in the anterior cingulate cortex (Fig. 2) and reported previously in tissue graft studies of developing limbic cortex (Barbe and Levitt, 1992). A schematic summary of the present results is presented in Figure 5.

\section{DISCUSSION}

The present analysis of the developmental topography of thalamocortical projections in the absence of a putative guidance molecule, ephrin-A5, demonstrates that thalamic afferents avoid certain territories because of the presence of local repulsive cues distributed regionally in the cerebral cortex. The role of the cortex in providing information for establishing specific connections and determination of anatomical and functional areal characteristics has been a subject of controversy. In the last few years, a variety of experimental strategies have been used to produce strong evidences that the cortex participates in a particularly instructive manner in establishing areal phenotypes that ultimately regulate afferent organization (Barbe and Levitt, 1992; Bolz and Götz, 1992; Mann et al., 1998; Nakagawa et al., 1999; Bishop et al., 2000; Vanderhaeghen et al., 2000; Hevner et al., 2001). This has been shown most recently in mutant mice in which deletion of dorsal telencephalic transcription factors $e m x 2$, pax6, or $\ln x 2$ resulted in aberrant expression of guidance molecules and errors in thalamocortical projections (Porter et al., 1997; Götz et al., 1998; Bishop et al., 2000; Mallamaci et al., 2000; Fukuchi-Shimogori and Grove, 2001). Although functional significance of the misexpressed axon guidance molecules has been inferred, direct assessment of the consequences of disrupted or absent molecular cues in vivo had not be investigated directly.

\section{Methodological considerations}

Our data indicate that the LD-labeled neurons in the ephrin-A5 $-/-$ mice, after neocortical labeling, represents errors in axon targeting. There are several reasons to support this conclusion. First, tracer injections in other somatic sensorimotor cortices, such as the posterior parietal cortex (PPC), label cells mostly in the lateral posterior nucleus, with very few neurons labeled in LD (Chandler et al., 1992; Reep et al., 1994). Injections rostral to PPC never label neurons retrogradely in LD and LP, but rather, only neurons in VB and Po. This is the specific region that we targeted in our studies avoiding contamination of PPC with the dye. The 


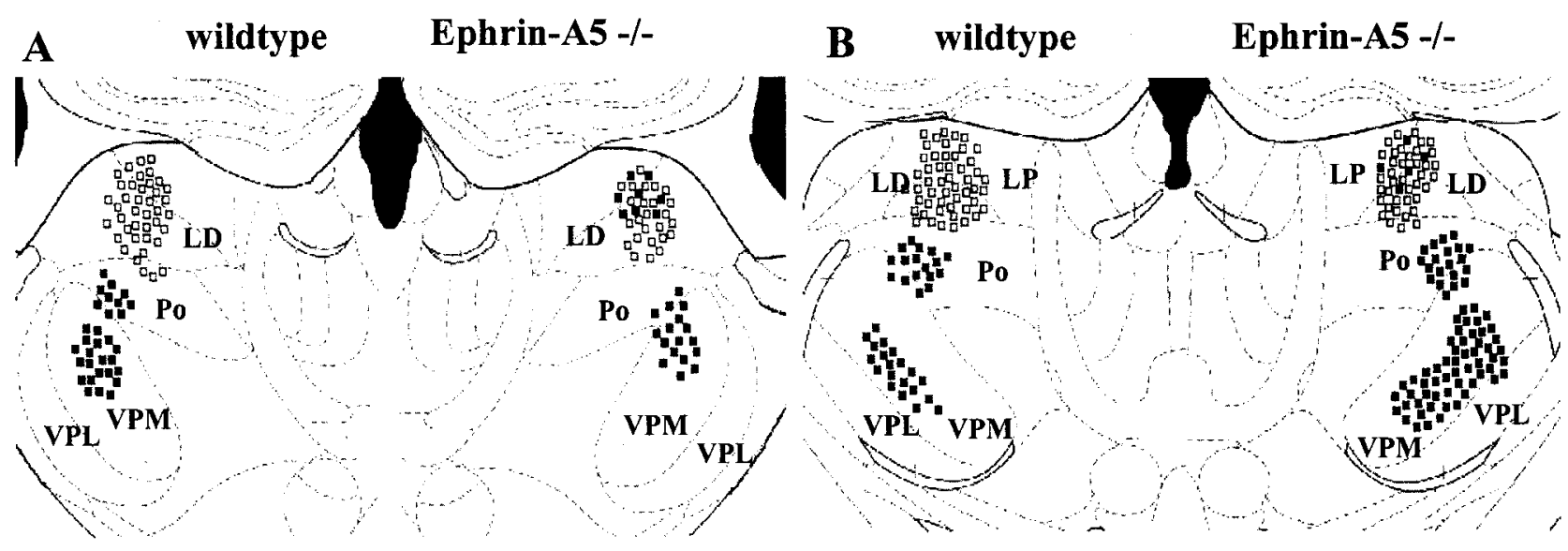

Figure 4. Double-labeling experiments. Retrogradely stained thalamic neurons after implantation of DiASP in the cingulate cortex (open squares) and DiI in the sensorimotor region ( filled squares). Composite drawings from three experiments. Left, Wild type; right, ephrin-A5 knock-out mice. A, interaural 2.23 , bregma $-1.46 ; B$, interaural 1.86 , bregma -1.95 . Note that, in the absence of ephrin-A5, a group of limbic thalamic cells are miswired and innervate the sensorimotor cortex. $V P L$, Ventral posterolateral nucleus; $V P M$, ventral posteromedial nucleus.

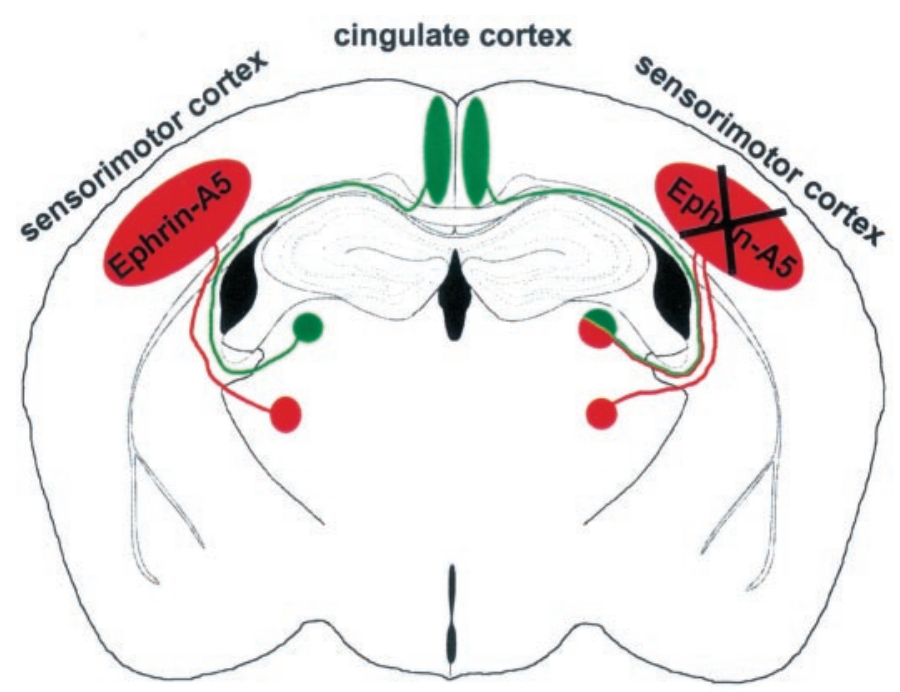

Figure 5. Schematic representation of thalamocortical projections in wild-type (left) and ephrin-A5 -/- (right) mice. Thalamic neurons in ventrobasal nuclei (red circle) project to the sensorimotor cortex (red ellipse), and limbic thalamic neurons in laterodorsal nuclei (green circle) project to the cingulate cortex (green ellipse). However, in knock-out animals, limbic thalamic neurons also formed additional projections to the sensorimotor cortex (indicated by red-green lines on the right). The portion of miswired cells was variable (see Table 1) and is overrepresented in this schematic figure. These data suggest that ephrin-A5 acts as a repulsive guidance cue that restricts limbic thalamic axons from innervating inappropriate cortical regions.

site of implantation of the dye crystals were very similar between ephrin-A $5+/+$ and $-/-$ mice.

Although 9 of 10 ephrin-A5 -/- mice had ectopically labeled cells in LD, there was interanimal variability in the percentage of ectopic cells. This variability is most likely attributable to the position and depth of the crystal placement in the cortex. In case $\mathrm{D}$, for example, in which we failed to identify ectopic neurons in $\mathrm{LD}$, there were substantially fewer cells labeled in VB when compared with other cases with injections in the somatosensory region. This case had a more superficial placement of the DiI crystal, thus producing incomplete labeling of layer 4 and resulting in an overall decrease in thalamic labeling. However, in cases
$\mathrm{B}$ and $\mathrm{E}$, a similar number of cells were labeled in VB and Po, but there was a more than fivefold difference in the number of miswired cells in LD. Thus, there also may be some variability in the penetrance of the phenotype between different animals.

\section{A role for repulsive guidance cues in cortical development}

There are a number of putative guidance molecules expressed in the embryonic cortex at the time thalamic axons arrive and thus could influence targeting and innervation of specific cortical areas. Gao et al. (1998) demonstrated in vitro that ephrin-A5 inhibited outgrowth of EphA5-expressing medial (limbic) thalamic neurons but not lateral (sensory) neurons. They first suggested that ephrin-A5 in the somatosensory region of developing mice could help guide medial thalamic axons to their correct cortical limbic targets. Recently, Vanderhaeghen et al. (2000) showed that ephrin-A5 influences the development of the barrel field in mice. Fibers originating from the medial part of the VB of the thalamus, which is poor in EphA4, innervate the most medial part of the barrel field, rich in ephrin-A5. Lateral VB regions, rich in EphA4 innervate lateral cortical regions, which are poor in ephrin-A5. In ephrin-A5 knock-out mice, although the topography map of the posteromedial barrel subfield is not altered, there is an abnormality in the size of the barrels; medial barrels are compressed and lateral barrels are expanded in area. These findings suggest that ephrin-A5 also could act as a positional label for map formation.

Mackarehtschian et al. (1999) reported that expression of ephrin-A5, detected by in situ hybridization, occurs in the rat cortex on embryonic day 17 (E17), $1 \mathrm{~d}$ after the arrival of thalamic fibers in the cortex. Based on these findings, the authors suggest that it is unlikely that ephrin-A5 guides the initial innervation of anterior and lateral regions of the cortex. Instead, this molecule could repel later-arriving thalamic axons from already innervated areas. Although this conclusion is still consistent with our findings, the timing of expression of sufficient biologically active protein is difficult to determine using in situ hybridization, which is not particularly sensitive for detecting low levels of transcript.

\section{Ephrin-A5 controls errors in limbic axon targeting}

We show here that ephrin-A5 knock-out mice have abnormalities in the innervation of the cortex by thalamic afferents. Although 
most of LD cells from ephrin-A5 -/- mice correctly innervate the medial limbic cortex, a non-overlapping subpopulation of LD neurons have misrouted axons, reaching neocortical areas. LD normally has dense projections to retrosplenial granular cortex, presubiculum and parasubiculum, and more modest innervation of cingulate cortex (Van Groen and Wyss, 1990, 1992). It has been postulated that LD plays a special role in integrating limbic function from different levels of the brain with few, if any, projections to the sensorimotor cortex (Ryszka and Heger, 1979; Barbe and Levitt, 1992 and references therein). We found that apparently separate axons, originating from different populations of LD neurons, innervate limbic and neocortical areas in ephrin-A5 - -1 mice. Axons from other thalamic nuclei that connect limbic areas, such as the anterior nuclear complex and mediodorsal nucleus, never enter S1 in ephrin $-/-$ animals. This is probably attributable to the anatomical organization of thalamocortical projections. Fibers originating in those nuclei have more rostral trajectories, whereas fibers from LD exit the thalamus to innervate the cortex in a similar trajectory as VB fibers (Bernardo and Woolsey, 1987; Van Groen and Wyss, 1992). This confirms the hypothesis that the expression of ephrin-A5 in the cortex is important for limbic axons to avoid errors in targeting. Our study does not address the timing of when the misrouting occurs, which will be important to determine to understand the underlying cause for only a subpopulation of neurons exhibiting mistargeting.

\section{Multiple guidance cues control thalamic axon targeting}

Our data also are consistent with multiple molecules participating in the targeting of limbic thalamic axons. For example, LAMP is expressed in limbic cortical areas and in experimental systems and acts as a positive guidance molecule for thalamic limbic axons (Barbe and Levitt, 1992; Mann et al., 1998). Thus, LAMP and other potential molecular cues, such as cadherins, could provide sufficient information for normal limbic thalamic axon targeting in the ephrin-A5 -/- cortex. It is possible that other ephrin ligands and receptors also could participate in the guidance of thalamocortical projections. However, ephrin-A4 is not expressed in the cortex at E17, and the pattern of distribution of ephrin-A3 is uniform in the cortical plate, with no apparent gradients or areal specificity (Mackarehtschian et al., 1999). Thus, it is unlikely that either of these ephrin family members contributes to the selective innervation of cortical areas, as we demonstrate for ephrin-A5. Gale et al. (1996) showed, however, that there is considerable promiscuity in receptor-ligand binding in this tyrosine kinase family. Thus, it is possible that other receptors, such as EphA3 and EphA4, could interact with ephrin-A5. However, these two receptors are expressed medially, dorsally, and ventrally in the thalamus. Only EphA5 has a much higher medial and dorsal expression and very low levels ventrally in the thalamus, consistent with medial axons avoiding domains of ephrin-A5 expression (Gao et al., 1998).

From the present study, it is clear that ephrin-A5 works in concert with other wiring molecules in the targeting of thalamocortical projections. The role of multiple cues will be tested shortly as additional mouse lines with targeted deletion of genes that encode putative guidance molecules become available. We predict that a combinatorial deletion of cues will result in a more severe phenotype, in which ectopic projections form with a much reduced normal thalamic innervation pattern.

\section{REFERENCES}

Agmon A, Yang Lt, Jones EG, O’Dowd DK (1995) Topological precision in the thalamic projection to neonatal mouse barrel cortex. J Neurosci 15:549-561.

Barbe MF, Levitt P (1992) Attraction of specific thalamic input by cerebral grafts depends on the molecular identity of the implant. Proc Natl Acad Sci USA 89:3706-3710.

Bernardo KL, Woolsey TA (1987) Axonal trajectories between mouse somatosensory thalamus and cortex. J Comp Neurol 258:542-564.

Bishop KM, Goudreau G, O'Leary DMM (2000) Regulation of area identity in the mammalian neocortex by Emx2 and Pax6. Science 288:344-349.

Bolz J, Götz M (1992) Mechanisms to establish specific thalamocortical connections in the developing brain. In: Development of the central nervous system in vertebrates (Sharma SC, Goffinet AM, eds), pp 173-187. New York: Plenum.

Brownlee H, Gao PP, Frisén J, Dreyfus C, Zhou R, Black IB (2000) Multiple ephrins regulate hippocampal neurite outgrowth. J Comp Neurol 425:315-322.

Chandler HC, King V, Corwin JV, Reep RL (1992) Thalamocortical connections of rat posterior cortex. Neurosci Lett 143:237-242.

Cheng HJ, Nakamoto M, Bergemann AD, Flanagan JG (1995) Complementary gradients in expression and binding of ELF-1 and MEK4 in development of the topographic retinotectal projection map. Cell 82:371-381.

Crandall JE, Caviness VS (1984) Thalamocortical connections in newborn mice. J Comp Neurol 228:542-556.

De Carlos JA, O'Leary DDM (1992) Growth and targeting of subplate axons and establishment of major cortical pathways. J Neurosci 12:1194-1211.

Domesick VB (1972) Thalamic relationships to the medial cortex in the rat. Brain Behav Evol 6:457-483.

Drescher U, Kremoser C, Handwerker C, Löschinger J, Noda M, Bonhoeffer F (1995) In vitro guidance of retinal ganglion cell axons by RAGS, a $25 \mathrm{kDa}$ tectal protein related to ligands for Eph receptor tyrosine kinases. Cell 82:359-370.

Drescher U, Bonhoeffer F, Müller BK (1997) The Eph family in retinal axon guidance. Curr Opin Neurobiol 7:75-80.

Fabri M, Burton H (1991) Topography of connections between primary somatosensory cortex and posterior complex in rat: a multiple fluorescent tracer study. Brain Res 538:351-357.

Franklin KBJ, Paxinos GT (1997) The mouse brain in stereotaxic coordinates. San Diego: Academic.

Fukuchi-Shimogori T, Grove EA (2001) Neocortex patterning by the secreted signaling molecule FGF8. Science 294:1071-1074.

Gale NW, Holland SJ, Valenzuela DM, Flenniken A, Pan L, Ryan TE, Henkemeyer M, Strebhardt K, Hirai H, Wilkinson DG, Pawson T, Davis S, Yancopoulos GD (1996) Eph receptors and ligands comprise two major specificity subclasses and are reciprocally compartmentalized during embryogenesis. Neuron 17:9-19.

Gao P-P, Yue Y, Zhang J-H, Cerreti DP, Levitt P, Zhou RP (1998) Regulation of thalamic neurite outgrowth by the Eph ligand ephrin-A5: implications in the development of thalamocortical projections. Proc Natl Acad Sci USA 95:5329-5334

Götz M, Stoykova A, Gruss P (1998) Pax6 controls radial glia differentiation in the cerebral cortex. Neuron 21:1031-1044.

Hevner RF, Shi L, Justice N, Hsueh Y, Sheng M, Smiga S, Bulfone A, Goffinet AM, Campagnoni AT, Rubenstein JL (2001) Tbr1 regulates differentiation of the preplate and layer 6. Neuron 29:353-366.

Knöll B, Zarbalis K, Wurst W, Drescher U (2001) (2001) A role for the Eph family in the topographic targeting of vomeronasal axons. Development 128:895-906.

Mackarehtschian K, Lau CK, Caras I, McConnell SK (1999) Regional differences in the developing cerebral cortex revealed by ephrin-A5 expression. Cereb Cortex 9:601-610.

Mallamaci A, Muzio L, Chan CH, Parnavelas J, Boncinelli E (2000) Area identity shifts in the early cerebral cortex of Emx2-/- mutant mice. Nat Neurosci 3:679-686.

Mann F, Zhukareva V, Pimenta A, Levitt P, Bolz J (1998) Membraneassociated molecules guide limbic and nonlimbic thalamocortical projections. J Neurosci 18:9409-9419.

Mann F, Peuckert C, Dehner F, Zhou R, Bolz J (2002) Ephrins regulate the formation of terminal axonal arbors during the development of thalamocortical projections. Development 129:3945-3955.

Molnár Z, Blakemore C (1991) Lack of regional specificity for connections formed between thalamus and cortex in coculture. Nature 351:475-477.

Molnár Z, Blakemore C (1995) How do thalamic axons find their way to the cortex? Trends Neurosci 18:389-397.

Nakagawa Y, Johnson JE, O'Leary DDM (1999) Graded and areal expression patterns of regulatory genes and cadherins in embryonic neocortex independent of thalamocortical input. J Neurosci 19:10877-10885.

Novak N, Bolz J (1993) Formation of specific efferent projections 
in organotypic slice cultures of rat visual cortex co-cultured with lateral geniculate nucleus and superior colliculus. Eur J Neurosci 5: $15-24$.

Porter FD, Drago J, Xu Y, Cheema SS, Wassif C, Huang SP, Lee E, Grinberg A, Massalas JS, Bodine D, Alt F, Westphal H (1997) Lhx2, a LIM homeobox gene, is required for eye, forebrain, and definitive erythrocyte development. Development 124:2935-2944.

Reep RL, Chandler HC, King V, Corwin JV (1994) Rat posterior parietal cortex: topography of corticocortical and thalamic connections. Exp Brain Res 100:67-84.

Ryszka A, Heger M (1979) Afferent connections of the laterodorsal thalamic nucleus in the rat. Neurosci Lett 15:61-64.

Stein E, Savaskan NE, Ninnemann O, Nitsch R, Zhou R, Skutella T
(1999) A role for the Eph ligand ephrin-A3 in entorhino-hippocampal axon targeting. J Neurosci 19:8885-8893.

Van Groen T, Wyss JM (1990) Connections of the retrosplenial granular a cortex in the rat. J Comp Neurol 300:593-606.

Van Groen T, Wyss JM (1992) Projections from the laterodorsal nucleus of the thalamus to the limbic cortices in the rat. J Comp Neurol 324:427-448.

Vanderhaeghen P, Lu Q, Prakash N, Frisén J, Walsh C, Frostig RD, Flanagan JG (2000) A Mapping label required for normal scale of body representation in the cortex. Nat Neurosci 3:358-365.

Wise SP, Jones EG (1978) Developmental studies of thalamocortical and commissural connections in the rat somatic sensory cortex. J Comp Neurol 175:187-208. 